\title{
Epidemiological investigation and case-control study: a Legionnaires' disease outbreak associated with cooling towers in Warstein, Germany, August-September 2013
}

A Maisa ${ }^{1}$, A Brockmann ${ }^{2}$, F Renken ${ }^{2}$, C Lück ${ }^{3}$, S Pleischl ${ }^{4}$, M Exner ${ }^{4}$, I Daniels-Haardt ${ }^{5}$, A Jurke

1. Department of Infectiology and Hygiene, NRW Centre for Health, Münster, Germany

2. Public Health Department, Soest, Germany

3. Institute for Medical Microbiology and Hygiene, National Consulting Laboratory for Legionella, University of Technology, Dresden, Germany

4. Institute for Hygiene and Public Health, University of Bonn, Bonn, Germany

5. Division Health Protection, Health Promotion, NRW Centre for Health, Münster, Germany

Correspondence: Annette Jurke (Annette.Jurke@lzg.nrw.de)

Citation style for this article:

Maisa A, Brockmann A, Renken F, Lück C, Pleischl S, Exner M, Daniels-Haardt I, Jurke A. Epidemiological investigation and case-control study: a Legionnaires' disease outbreak associated with cooling towers in Warstein, Germany, August-September 2013. Euro Surveill. 2015;20(46):pii=30064. DOI: http://dx.doi. org/10.2807/1560-7917.ES.2015.20.46.30064

Article submitted on 23 September 2014 / accepted on 13 April 2015 / published on 19 November 2015

Between 1 August and 6 September 2013, an outbreak of Legionnaires' disease (LD) with 159 suspected cases occurred in Warstein, North Rhine-Westphalia, Germany. The outbreak consisted of 78 laboratoryconfirmed cases of LD, including one fatality, with a case fatality rate of $1 \%$. Legionella pneumophila, serogroup 1, subtype Knoxville, sequence type 345, was identified as the epidemic strain. A case-control study was conducted to identify possible sources of infection. In univariable analysis, cases were almost five times more likely to smoke than controls (odds ratio (OR): 4.81; 95\% confidence interval ( $\mathrm{Cl}):$ 2.33-9.93; $\mathrm{p}<0.0001)$. Furthermore, cases were twice as likely to live within a $3 \mathrm{~km}$ distance from one identified infection source as controls (OR: 2.14; 95\% Cl: 1.09-4.20; $p<0.027)$. This is the largest outbreak of LD in Germany to date. Due to a series of uncommon events, this outbreak was most likely caused by multiple sources involving industrial cooling towers. Quick epidemiological assessment, source tracing and shutting down of potential sources as well as rapid laboratory testing and early treatment are necessary to reduce morbidity and mortality. Maintenance of cooling towers must be carried out according to specification to prevent similar LD outbreaks in the future.

\section{Background}

Legionnaires' disease (LD) results mainly from inhalation of aerosols containing the bacterium Legionella pneumophila, which may cause atypical severe pneumonia [1]. The infectious agent is not transmitted from person to person. The incubation period normally ranges from two to 10 days, but may be up to 20 days in rare cases [2]. A less severe form with influenzalike symptoms, also caused by Legionella, is known as Pontiac fever. The bacterium is found ubiquitously in freshwater environments, but man-made environments such as cooling towers provide advantageous conditions for bacterial growth [1]. Advanced age, male sex, heavy smoking and several underlying diseases have been described as risk factors for acquiring LD [3]. In 2011 L. pneumophila was classified as one of the highest-priority infectious disease pathogens of public health concern in Germany [4]. In the German mandatory notification system, the number of reported sporadic cases of LD in North Rhine-Westphalia (NRW) remained stable in recent years, with a mean of 115 cases per year from 2008 to 2012 [5]. The last big outbreak of LD in Germany took place in Ulm/Neu-Ulm during December 2009 and January 2010, with 64 cases, including five fatalities, and was likely to have been caused by a contaminated cooling tower $[6,7]$.

On 14 August 2013, the regional public health office in Soest was notified of an unusual cluster of patients with atypical severe pneumonia of unknown aetiology, who had been admitted to a local hospital in Warstein. After one patient died of an atypical pneumonia on 14 August, extensive testing for legionellosis had been initiated. The first positive test result was reported on 19 August as per the German Infection Protection Act $[5,8]$. Between 10 and 19 August, almost 70 suspected acute LD infections were retrospectively notified to the local public health office in Soest and reported to the NRW Centre for Health. Only later did it become clear that the outbreak had started by 1 August, with 159 suspected cases in total, including 78 laboratoryconfirmed cases, as of 6 September (Figure 1). Usually only a few cases per month are reported at the state level and between 2008 and 2012 a mean of 10 cases 
per month were notified in NRW (range: 2-29). Of these, only three cases (one in 2008 and two in 2010) occurred in the region of Soest.

The Soest public health office consulted an expert team from the World Health Organization (WHO) Collaborating Centre for Health Promoting Water Management and Risk Communication at the University of Bonn's Institute for Hygiene and Public Health, who provided their expertise to help to investigate and eliminate the source of the outbreak. Furthermore, the Soest public health office contacted the NRW Centre for Health to support the epidemiological investigations to determine the magnitude of the outbreak in the affected region, to study the risk factors for LD and to find analytical evidence for suspected environmental sources. The German national consultant laboratory for Legionella at the University of Dresden was involved in laboratory confirmation and typing of patient and environmental Legionella strains.

\section{Methods}

\section{Case definition}

Initially cases were defined according to the German case definition as persons suffering from pneumonia, with onset of disease between 1 August and 6 September 2013 and living in or around Warstein. The German case definition includes laboratory-confirmed cases as well as cases without laboratory confirmation. The latter must both fulfil the clinical criterion and be epidemiologically linked to the outbreak, taking into account an incubation period of 2 to 10 days $[8,9]$. This resulted in 159 suspected cases including two fatalities with atypical pneumonia in this outbreak.

To allow comparison of this event with other outbreaks, we applied the European case definition for describing the outbreak and further analysis, which includes persons meeting the clinical criterion and at least one laboratory criterion for a probable or confirmed case, resulting in 78 laboratory-confirmed cases, including one fatality [10].

\section{Case-control study}

A case-control study was conducted to find evidence for or against potential sources. Controls were recruited from and around Warstein and were interviewed by random-digit dialling by telephone. Numbers were chosen randomly and incremented by 5 for the next call. Approximately 150 numbers could not be reached, and of the 330 people reached, 215 eligible participants agreed to be part of the study. Inclusion criteria were residence and/or stay in Warstein between 1 and 21 August 2013, as 10 August was initially assumed to be the start of the outbreak. Exclusion criteria were fever two weeks before the start of the outbreak and/ or antibiotic therapy. All participants provided verbal informed consent.
Data were analysed from the 78 laboratory-confirmed cases who met the European case definition. Of these, 75 were age- (+ / -5 years) and sex-matched with a 1:1 ratio for cases and controls.

An initial exploratory questionnaire was designed by the local health office and the NRW Centre for Health to interview patients and narrow down potential sources of infection. Cases and controls were interviewed using an amended analytical questionnaire to detect common activities, places visited and habits which might expose them to LD. The questionnaires were customised to the outbreak location, and participants were questioned about personal details, medical history and whereabouts, including proximity to locations that are typical for acquiring LD, such as whirlpools. Cases were asked to recall the 14 days preceding disease onset, whereas controls provided information for the time period since 1 August.

\section{Environmental investigations}

Relevant industrial plants were quickly identified in cooperation with the municipal public regulatory agency, and 68 cooling systems were inspected in and around Warstein. More than 880 environmental samples were collected and analysed at the University of Bonn and the consultant laboratory in Dresden, respectively (data not shown). During and after the outbreak, 26 municipal tap water samples were analysed. As of 21 August, possible contamination sources within industrial facilities had been inspected under the expertise of the environmental expert team and shut down for sampling and disinfection. Company operators were instructed not to run cooling towers or similar before proper disinfection.

Temperature, rainfall and wind data were obtained from the German Meteorological Service (Deutscher Wetterdienst, DWD) of the Federal Ministry of Transport and Digital Infrastructure.

Linear distances between cases or controls and the potential sources of the contaminated aerosols were calculated using an online calculation tool and included in the analysis [11].

\section{Laboratory investigations}

Urinary antigen was detected via Binax ELISA (Virotech Sekisui, Germany) as per manufacturer's instruction. Respiratory samples were cultured on selective and non-selective BCYE-Agar, in dilutions and/or after heat treatment for 3 minutes at $60^{\circ} \mathrm{C}$. Legionella DNA was detected by the Euroclone PCR assay (Virotech Sekisui, Germany) as per manufacturer's instruction. Water samples were cultured according to the ISO 11731 guideline [12]. Isolated strains were serotyped with the latex agglutination assay (Oxoid, Germany) and further by the Dresden panel of monoclonal antibodies [13]. Strains belonging to the monoclonal subtype Knoxville were further genotyped by the standard sequence-based typing method (SBT) [14]. The direct 
SBT protocol for culture-independent subtyping was applied on culture negative, but PCR positive respiratory samples [14].

\section{Statistical methods}

Notification data was retrieved from the state-level SurvNet database at the NRW Centre for Health [5] and was used for analysis in addition to the data retrieved from the questionnaires. Excel (Microsoft) and SPSS 22 (IBM) were used for data management and statistical analyses. Based on univariable logistic regression and biological or epidemiological plausibility, we determined exposures that were associated with being a case by including those with $p<0.1$ in the multivariable analysis. We conducted an unmatched forward stepwise multivariable analysis using logistic regression. Odds ratio (OR), 95\% confidence interval $(\mathrm{Cl})$ and likelihood ratio $\mathrm{p}$ values were calculated in the univariable and multivariable models and values of $p<0.05$ were considered statistically significant.

\section{Results}

\section{Descriptive epidemiology}

The outbreak comprised 78 laboratory-confirmed cases (50 males and 28 females) of LD including one fatality, who were living in the Warstein region and had an onset of disease between 1 August and 6 September 2013 (Figure 1 and Figure 2). Due to severity of illness or underlying medical conditions, not all patients could be interviewed in detail.

Suspected cases $(n=81)$ are indicated as blue dots and laboratory-confirmed ones $(n=78)$ as yellow, displayed by place of residence. Six cases (including three laboratory-confirmed) are not included in this map, because they were resident outside the displayed area. Potential sources A, B, C and D are indicated as black dots with white letters. Source $D$ represents the local river water, which ranges from source $B$ via $C$ and $A$ to $\mathrm{D}$ and beyond both points.

The median age of cases was 63 years (range: 19-94 years). Of 78 cases, 71 were hospitalised (91\%); 12 of whom were in intensive care (17\%) and 8 of whom required intubation (11\%). Hospital admission dates were available for 68 cases. Median duration of hospitalisation was 9.5 days (range: $3-50$ days) with $25 \%$ of patients being hospitalised for 14 or more days. Of 66 patients, 47 were on medication and/or had comorbidities $(71 \%)$. All 78 cases suffered from pneumonia, 65 patients provided self-reported information about additional symptoms including fever (95\%, $n=62)$, influenza-like symptoms $(52 \%, n=34)$, cough $(43 \%$, $n=28)$, gastrointestinal symptoms ( $28 \%, n=18)$, headache $(11 \%, n=7)$ and respiratory problems $(8 \%, n=5)$. Smoking status was provided by 65 cases: 41 were smokers (63\%), of whom 26 were male $(63 \%)$.

The case fatality rate was $1 \%$. In Warstein the incidence of LD infections per 1,000 inhabitants was 3.74 for male and 2.07 for female patients [15]. This incidence was higher for males than females in each age group and increased with age, especially within the male group aged older than 80 years. Nevertheless, the male-tofemale ratio of $1.68: 1$ is lower than previously reported [16].

Surprisingly, two cases were under 40 years of age (19 and 31 years-old); both were male and living within a 4 $\mathrm{km}$ radius of one identified source (source A; Figure 2 ). One was a smoker; the other did not provide information about smoking status.

\section{Case-control study}

The case-control study involved 75 cases (47 male, 28 female), who contracted LD between 1 August and 6 September 2013, and 75 age- (+ / -5 years) and sexmatched controls. Median age was 63 years (range: 19-93 years) for cases and 64 years (range: 18-90 years) for controls. Within the case group, $64 \%$ were smokers ( $n=41$ of 64 ) compared with just $27 \%$ of controls ( $n=20$ of 74 ). Smoking was associated with the highest odds of developing LD in univariable analysis (OR: 4.81; 95\% Cl: 2.33-9.93; p < 0.0001; Table). Although $70 \%$ of cases had underlying diseases and/ or were on medication therapy $(n=44$ of 63) compared with $73 \%$ of controls ( $n=54$ of 74 ), this did not prove to be a significant factor for becoming ill (univariable analysis: OR: 0.86; 95\% Cl: 0.41-1.80; $\mathrm{p}=0.69$; Table).

While the cases resided in and around Warstein, most of them worked or went shopping within the Warstein town area and the town centre, which comprises a small area no larger than $6 \mathrm{~km}^{2}$ [17]. Shopping in Warstein resulted in apparently protective odds (univariable analysis: OR: $0.21 ; 95 \% \mathrm{Cl}$ : 0.082-0.54; $\mathrm{p}<0.001$ ), which probably represents only a short stay in enclosed buildings. The main connecting road between Warstein and Belecke (approximately $5 \mathrm{~km}$ ) was also added to the data analysis, but its use was not significantly associated with LD cases. There was no evidence of infections occurring in the workplace. Most patients were retired, which is also apparent from the affected age groups. LD could not be connected to car washes, springs or other aerosol-producing areas. Very few people visited swimming pools, saunas or similar. Equally, no increased frequency of visiting dentists or local general practitioners could be observed. There was no evidence of infections being linked to large events in and around town.

Results of the linear distances between cases and controls to the potential sources $A$ and $B$ indicate that cases were twice as likely to live $<3 \mathrm{~km}$ of source $A$, which is located closer to the town centre than source B (Figure 2), without considering topography of the area or taking into account wind directions and strengths (univariable analysis: OR: $2.14 ; 95 \% \mathrm{Cl}: 1.09-4.2 ; \mathrm{p}=0.027$ ); Table). The distance from source $A$ to source $B$ is around $5.5 \mathrm{~km}$. Source A is located north and Source B south of the town, but wind directions were favourable for 
Epidemiological curve for Legionnaires disease outbreak, Warstein, Germany, August 2013

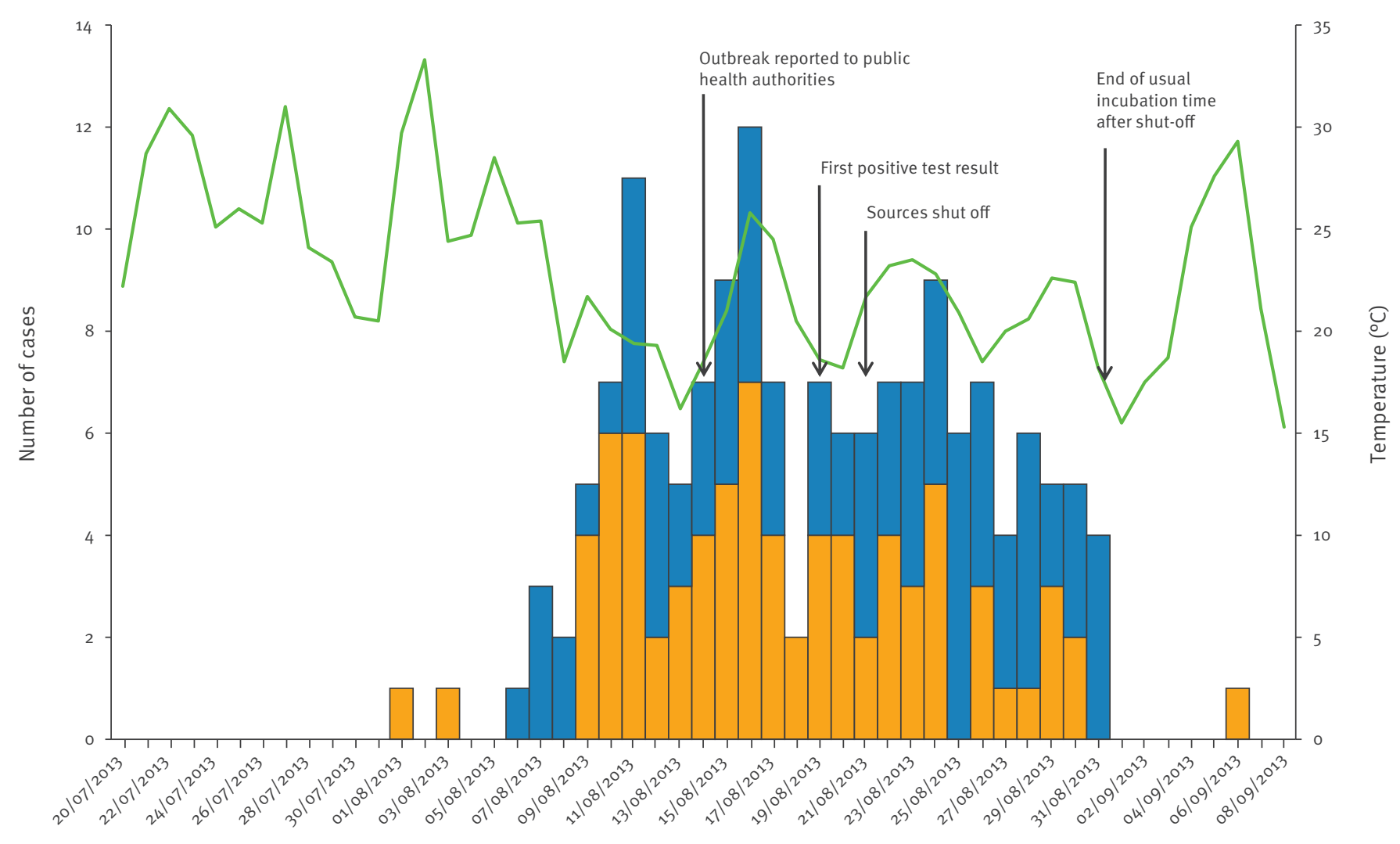

Date

Positive
Negative test result for Legionella pneumophila

both sources, potentially spreading aerosols into the town centre before 21 August. However, the prevailing wind direction was from the south. Compared with the distance to source $A$, the odds of cases living closer to source $B$ is low, resulting in an apparently protective odds in univariable analysis (OR: 0.36 ; $95 \% \mathrm{Cl}$ : $0.18-$ $0.7 ; p=0.003)$.

In the multivariable analysis only smoking remained a risk factor for developing LD, whereas shopping in Warstein town centre seemed to be a protective factor (Table).

\section{Environmental investigations}

The epidemic strain of Legionella was found in four sources: two cooling towers, one sewage plant and one river water.

On 26 August the first positive result from the sampled industrial facilities was received [18], which confirmed that a cooling tower from one source (Source A; $2.84 \times 10^{5}$ colony forming units (cfu)/100 ml) was contaminated by several subtypes of $L$. pneumophila, with the epidemic strain representing $10 \%$ of those. In addition to source $A$, a second cooling tower from a different company (source B) tested positive for the epidemic strain ( $\leq 100 \mathrm{cfu} / 100 \mathrm{ml}$ ). Immediately afterwards the epidemic strain was also detected at the municipal sewage plant (source $C ; \geq 5 \times 10^{6} \mathrm{cfu} / 100 \mathrm{ml}$ ) as well as in the river water (source $D ; \leq 3 \times 10^{4} \mathrm{cfu} / 100 \mathrm{ml}$ ), which consequently involved the assistance of the environmental authorities. The carbohydrate-rich wastewater of source $B$ and the activation basin of the pretreatment plant provided an ideal environment for bacterial growth.

During and after the outbreak 26 municipal tap water samples were analysed, all of which were negative.

Prior to the outbreak there were 12 warm days (maximum temperature $\geq 25^{\circ} \mathrm{C}$ ) between 21 July and 7 August (Figure 1), which may have helped initiate the spread of $L$. pneumophila from cooling towers. Warm weather conditions with temperatures from $25^{\circ} \mathrm{C}$ to $30{ }^{\circ} \mathrm{C}$ lasted until the first week of August.

Wind direction data was dichotomised and roughly classified as mainly from a northerly $\left(270^{\circ}\right.$ to $360^{\circ}$ and $0^{\circ}$ to $89^{\circ}$ ) or southerly ( $90^{\circ}$ to $269^{\circ}$ ) direction. Between 21 July and 20 August, $78 \%$ of the hourly wind 
Geographical distribution of cases, Legionnaires' disease outbreak, Warstein, Germany, August 2013 (n=78)

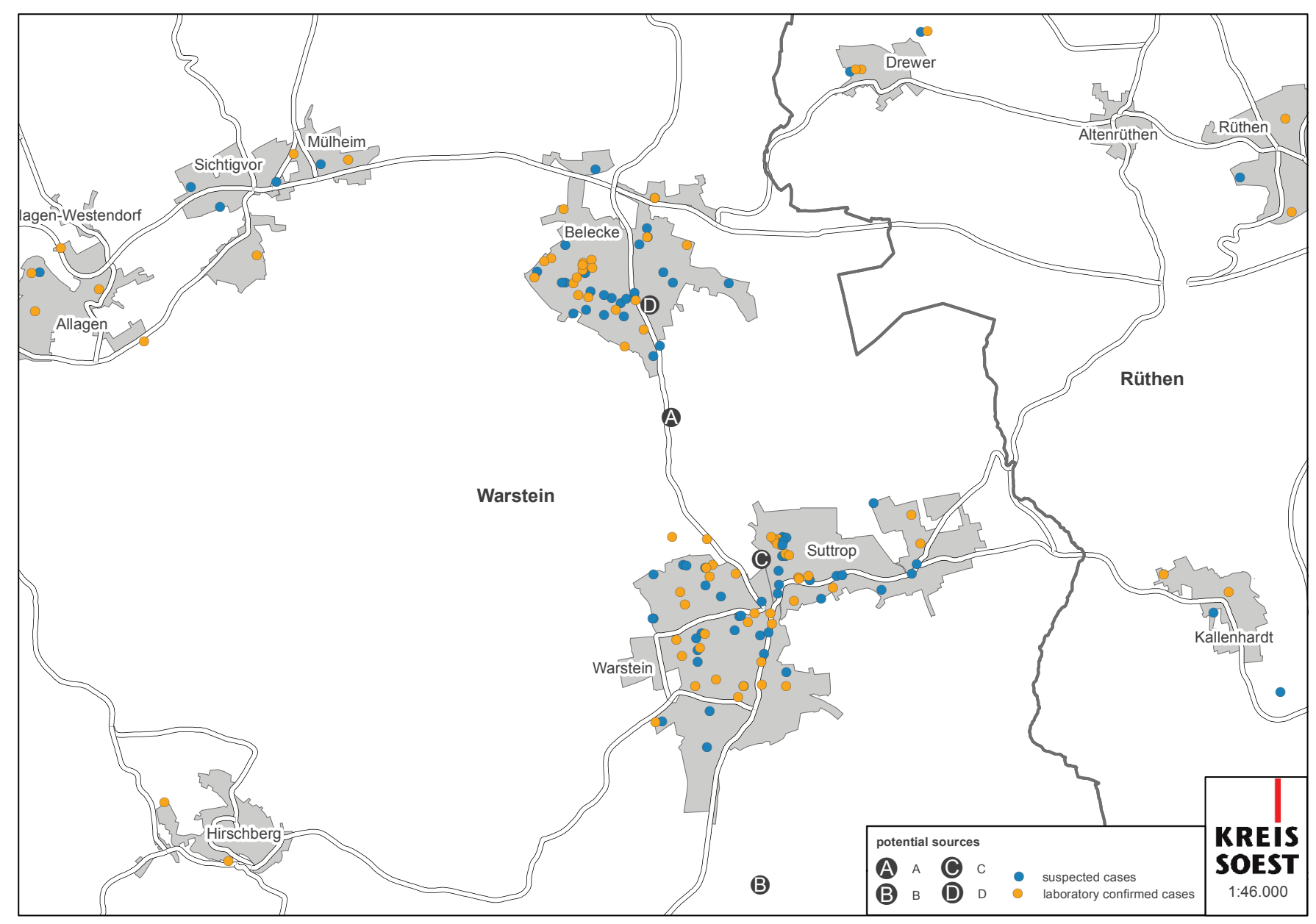

Suspected cases are indicated as green dots and laboratory-confirmed ones as red, displayed by place of residence. Six cases (including three laboratory-confirmed) are not included in this map, because they were resident outside the displayed area. Potential sources $A$, B, $C$ and $D$ are indicated as black dots with white letters. Source D represents the local river water, which ranges from source $B$ via $C$ and $A$ to $D$ and beyond both points.

direction measurements show wind from the south, with eight days showing wind only from south.

\section{Laboratory investigations}

On 19 August the local public health department received the first positive laboratory result for $L$. pneumophila serogroup 1 sampled from a patient.

L. pneumophila, serogroup 1, subtype Knoxville, sequence type (ST) 345, was identified as the epidemic strain of this outbreak, and could be isolated from seven patients as well as several environmental samples from two cooling towers, a municipal sewage plant and a river water source in Warstein $[13,19]$. Complete or partial sequences compatible to ST 325 were obtained from three further cases.

One culture-confirmed case with disease onset on 6 September was included in the outbreak as the presence of the epidemic strain could be verified for this person, suggesting an unusually long incubation period, which has been observed to be 20 days in exceptional cases [2].

\section{Outbreak management}

The local health authorities conducted commendable press work with regular updates on the situation and public information. In addition to daily press releases, a helpline for the general public was set up by the Soest local health office.

Public health measures were discussed during several teleconferences between responsible authorities and expert teams. In addition, the NRW Centre for Health updated the other state health authorities in Germany and the Robert Koch Institute via regular epidemiological teleconferences about the outbreak. The Robert Koch Institute released a short summary in their weekly epidemiological bulletin to inform public health authorities in Germany about the outbreak and to promote quick and targeted diagnostics as well as therapy for suspected cases possibly linked to Warstein [20]. 
Univariable and multivariable analysis of probable exposure factors, Legionnaires' disease outbreak, Warstein, Germany, August-September 2013

\begin{tabular}{|c|c|c|c|c|c|c|c|c|c|c|}
\hline \multirow[b]{2}{*}{ Exposure } & \multicolumn{3}{|c|}{ Cases } & \multicolumn{3}{|c|}{ Controls } & \multicolumn{2}{|c|}{ Univariable } & \multicolumn{2}{|c|}{ Multivariable } \\
\hline & Exposed & Total & $\%$ & Exposed & Total & $\%$ & $\begin{array}{c}\text { OR } \\
(95 \% \mathrm{Cl})\end{array}$ & $p$ & $\begin{array}{c}\text { OR } \\
(95 \% \mathrm{Cl})\end{array}$ & $p$ \\
\hline Male sex & 47 & 75 & 62.7 & 47 & 75 & 62.7 & 1 & 1 & \multicolumn{2}{|l|}{ a } \\
\hline $\begin{array}{l}\text { Drugs and/or } \\
\text { Comorbidity }\end{array}$ & 44 & 63 & 69.8 & 54 & 74 & 73.0 & $\begin{array}{c}0.86 \\
(0.41-1.80)\end{array}$ & 0.69 & \multicolumn{2}{|l|}{ a } \\
\hline Smoker & 41 & 64 & 64.1 & 20 & 74 & 27.0 & $\begin{array}{c}4.81 \\
(2.33-9.93) \\
\end{array}$ & $<0.0001$ & $\begin{array}{c}5.11 \\
(2.31-11.32) \\
\end{array}$ & $<0.0001$ \\
\hline $\begin{array}{l}\text { Attending } \\
\text { event }\end{array}$ & 7 & 59 & 11.9 & 5 & 75 & 6.7 & $\begin{array}{c}1.89 \\
(0.57-6.27) \\
\end{array}$ & 0.30 & \multicolumn{2}{|l|}{ a } \\
\hline $\begin{array}{l}\text { Shopping in } \\
\text { Warstein }\end{array}$ & 41 & 61 & 67.2 & 68 & 75 & 90.7 & $\begin{array}{c}0.21 \\
(0.08-0.54) \\
\end{array}$ & $<0.001$ & $\begin{array}{c}0.18 \\
(0.06-0.50)\end{array}$ & $<0.001$ \\
\hline $\begin{array}{l}\text { Travelling via } \\
\text { main road }\end{array}$ & 40 & 57 & 70.2 & 48 & 74 & $64 \cdot 9$ & $\begin{array}{c}1.28 \\
(0.61-2.68)\end{array}$ & 0.52 & \multicolumn{2}{|l|}{ a } \\
\hline $\begin{array}{l}\text { Distance } \\
\text { to source } \\
\text { A }<3 \mathrm{~km}\end{array}$ & 52 & 75 & 69.3 & 37 & 72 & 51.4 & $\begin{array}{c}2.14 \\
(1.09-4.20)\end{array}$ & 0.027 & \multicolumn{2}{|l|}{ b } \\
\hline $\begin{array}{l}\text { Distance } \\
\text { to source } \\
B<3 \mathrm{~km}\end{array}$ & 25 & 75 & $33 \cdot 3$ & 42 & 72 & 58.3 & $\begin{array}{c}0.36 \\
(0.18-0.70)\end{array}$ & 0.003 & \multicolumn{2}{|l|}{ b } \\
\hline
\end{tabular}

$\mathrm{Cl}$ : confidence interval; OR: odds ratio.

${ }^{a}$ Not considered for multivariable analysis $(p \geq 0.1)$.

${ }^{b}$ Not included in the final model by the stepwise forward variable selection procedure.

One confirmed case of LD was reported outside of Warstein with a possible connection to the outbreak, but could not be linked epidemiologically. Another person living in Sweden was suspected to be suffering from LD after visiting Warstein during the outbreak [18]. This person had already been interviewed and had neither pneumonia nor other typical LD symptoms and thus no laboratory testing had been initiated. The NRW Centre for Health tracked this probable case via the Robert Koch Institute and the national focal point in Sweden, but did not reveal an official notification of LD within the country of residence; hence this person was not linked to the outbreak.

As a measure of infection prevention (according to article 16 of the German Infection Protection Act [21]) the local authorities decided on 27 August to cancel a major event which was expected to attract 150,000 visitors. Intensified public health measures were effective as of 30 August, when the local health authorities announced that unnecessary travel to Warstein should be avoided until the definitive source had been identified and that people developing symptoms should seek medical attention. The public health recommendations ended after completion of protective measures at the environmental sources on 18 September.

\section{Discussion}

Here we describe the largest community-associated outbreak of LD in Germany to date. This outbreak resulted in 159 suspected cases including 78 laboratory-confirmed cases. Several other previous outbreaks within Europe, including those in Spain, the
United Kingdom and the Netherlands, caused larger numbers of LD cases compared with the outbreak in Warstein [22-24]. We cannot exclude the possibility that suspected cases without laboratory confirmation were suffering from something other than LD. However, due to surveillance data and the hospitalisation of a large number of people, an unusual cluster of LD was suspected. Hence, all cases with pneumonia were initially linked epidemiologically to the outbreak. To make our analysis applicable to other countries, the European case definition was applied, so our analysis involved 78 laboratory-confirmed cases including one fatality.

The case-control study helped to exclude potential sources of infection. The main results reveal a higher incidence rate within the male population. Also, smoking was a high risk factor for becoming infected. Data analysis of the questionnaire showed that movement of both cases and controls was very limited: with only few reported travelling while some had not left their homes at all. Immobile cases were most likely infected via airing their homes, which is not unusual during hot summer periods. Shopping in Warstein resulted in apparently protective odds, which could be due to being indoors and not exposed to aerosols outside. Apart from that it gives evidence against the shopping centre area being a source of infection, a possibility which had been considered at the beginning of the outbreak. Although the case-control study shows a higher risk for LD for people living closer to source $A$, this does not exclude people living further away, who may still have visited the town centre and suffered from LD. 
More than one potential source contaminated by the outbreak strain was identified and although no definite conclusion could be made, industrial cooling towers belonging to two companies were most likely responsible for this outbreak. Due to the shutting off of potential sources, together with the topographic location of Warstein, further spread and transmission of bacteria could be contained quite rapidly.

As in previous outbreaks, the epidemic strain reacted with the monoclonal antibody Mab 3-1. Such strains have a higher hydrophobic surface in comparison with other Legionella strains, which might be the reason for the high transmissibility and survival in aerosols [25]. Nevertheless, according to the SBT database for $L$. pneumophila the outbreak strain was previously associated with only eight sporadic cases of pneumonia worldwide and is therefore not a very common cause of Legionella pneumonia [14].

Source A could not be solely or primarily responsible for the magnitude of this outbreak, due to the height, size and properties of its cooling tower. Also, source A was contaminated by several subtypes of $L$. pneumophila, only $10 \%$ of which were the epidemic strain. Confirmation of the outbreak strain of L. pneumophila in several sources led to the hypothesis that source $B$ contaminated source C via partially treated sewage, which then drained treated wastewater into source $D$. A series of events in combination is most likely responsible for the outbreak as source A was almost certainly contaminated using water from source $D$ to run their cooling tower. In addition, wind conditions were favourable for spreading contaminated aerosols via both cooling towers in source A and B. However, source B may have been responsible for some cases near source $A$, as the predominantly southerly wind could have transported the pathogen 7 to $10 \mathrm{~km}$ by aerosols from source B into the region $<3 \mathrm{~km}$ around source A [26]. Apparently protective odds for the region $<3 \mathrm{~km}$ around source B support a further transmission of aerosols. It should also be noted that the area around source $B$ is mostly uninhabited, including only a small part of the town centre north of the source.

Sewage plants are known to be a source for L. pneumophila and have been described as a source of LD infections [27]. During an outbreak of LD in Norway, a biological treatment plant was identified as an indirect infection source, contaminating an air scrubber, which acted as an infection vehicle. Eight of nine employees at this plant were seroresponders with a working distance from the plant less than or equal to $200 \mathrm{~m}$ [28], similar to our observations regarding exposure distance to aerosols of the treatment plant (Source C). However, no employees of the local sewage plant came down with symptoms or disease in our study.

The low case fatality rate of $1 \%$ compared with the European mean of $10 \%$ [16] may be mostly due to immediate clinical management of patients at the local hospitals in Warstein as well as the effective public health measures from the health department in Soest. Still, the capacity of the local hospital was stretched to its limits, so that patients had to be allocated to surrounding hospitals. The immunochromatographic urinary antigen tests initially used were not sufficiently sensitive, and so at the start of the outbreak many antigen tests were false negatives. Retesting of urine samples via a more sensitive method (ELISA) was subsequently performed for more than 500 samples at the consultant laboratory and thus the number of laboratory confirmed cases increased during and after the outbreak. Nevertheless, only 78 of 159 patients had a positive test result, which may be due to rapid initiation of therapy. Fields et al. reviewed studies showing that antigen was detected in more than $80 \%$ of patients between day 1 and 14 after onset of symptoms and $100 \%$ after day 14 up to more than 300 days in exceptional cases. However, in some patients, who had been on therapy for four days, antigen was no longer detectable [1]. Immediate initiation of therapy may have been one reason for the low number of positive test results during this outbreak, as well as delayed utilisation of another more sensitive test. Moreover, concentration of urine samples may lead to increased sensitivity [1]. Also, test sensitivity depends on severity of infection [29].

The outbreak in Warstein was attended by a series of uncommon events. Involvement of more than one source made tracing difficult. Cooling towers have previously been described as posing a risk for LD outbreaks, and so the search for the source focused on relevant industrial facilities. Besides cooling towers at big industrial facilities, other sites should be considered, such as environmental locations (e.g. river water as a water source for cooling towers) and biological waste plants. Furthermore, companies and industrial workers should be better trained in maintenance of their facilities, so as to avoid the occurrence of similar outbreaks [30].

Decision-making on public health measures must be supported by all the relevant authorities and should stay in effect until all potential sources have been closed. Because of the outbreak, a large public event in Warstein (150,000 visitors expected) was cancelled. According to LD case numbers at that time, it was estimated that had the event gone ahead, there would have been around 800 additional suspected cases and consequently further fatalities. This reinforced the recommendation not to visit Warstein unless necessary. The main issue leading to the decision to cancel this event was the risk of elderly visitors in particular being infected and receiving late or untargeted treatment from their local general practitioners, which could have resulted in more severe illness or even more deaths.

One limitation of our study is that the outbreak was recognised and notified quite late and so there were many retrospectively notified suspected cases and 
fewer laboratory-confirmed ones. Nevertheless, applying the German case definition, 159 suspected cases were included in this outbreak on a national level. Considering that the true incidence of LD cases in Europe is estimated to be much higher than reported [2] and also that cases in this outbreak were probably underdiagnosed, the German case definition seemed suitable for this outbreak situation, making it likely that no cases were missed.

This study demonstrates how important a quick assessment of the situation is to limit morbidity and mortality rates. Rapid effective testing and early clinical management are as important as the source tracing in such an outbreak, as well as seeking cooperation and using the expertise of all responsible authorities including political ones. Correct identification and prompt interview of cases and controls may help to exclude possible sources and focus on relevant exposure sites. Most importantly, a collaborative approach involving several departments with different expertise and areas of responsibility proved to be very effective in quickly containing this outbreak.

\section{Acknowledgements}

The authors would like to acknowledge the contributions of all members of the outbreak investigation team, especially S Kroenke, F Hoffmann, M Lunemann, R Grosse, R Moers, J Jarisch, G Paetschke, M Moenikes, C Rösing, LR Irrgang, KD Lönnecke, M Gödde, R Hellermann, A Ebeling, B Müller, $\mathrm{R}$ Wrede, $\mathrm{N}$ Hurtig, $\mathrm{G}$ Mertsch and others. We would like to thank the local authorities for their assistance in the investigation of cases, the local hospital staff and the members of Infectiology and Hygiene at the NRW Centre for Health for interviewing study participants. We gratefully acknowledge the laboratory staff in Bonn: F Brändle, B Göing, and Dresden, M Petzold and K Lück. We would also like to thank $\mathrm{U}$ Buchholz and colleagues from the Robert Koch Institute for expert advice and support. The DWD provided meteorological data and maps were produced by R Moers and colleagues at the local health office in Soest. No funding was received for the present work.

\section{Conflict of interest}

None declared.

\section{Authors' contributions}

AM and AJ drafted the manuscript and IDH critically reviewed the paper. AJ, AM and IDH designed the case-control study, $A M$ and $A J$ performed the epidemiological analysis and interpreted the results. ME and SP were responsible for source tracing, environmental laboratory analysis and risk assessment, and CL for typing clinical and environmental strains of legionella. Recommendation of public health measures was discussed by FR, $A B, I D H, A J, M E . A J, A M, I D H, F R$ and $A B$ interpreted notified cases and epidemiological relevance.

\section{References}

1. Fields BS, Benson RF, Besser RE. Legionella and Legionnaires' disease: 25 years of investigation.Clin Microbiol Rev.
2002;15(3):506-26. DOI: 10.1128/CMR.15-3.506-526.2002 PMID: 12097254

2. European Centre for Disease Prevention and Control (ECDC). Technical Document. European Legionnaires' Disease Surveillance Network (ELDSNet). Operating procedures Stockholm: ECDC; 2012. Available from: http://ecdc.europa. eu/en/publications/publications/1202-ted-eldsnet-operatingprocedures.pdf

3. Marston BJ, Lipman HB, Breiman RF. Surveillance for Legionnaires' disease. Risk factors for morbidity and mortality. Arch Intern Med. 1994;154(21):2417-22. DOI: 10.1001/ archinte.1994.00420210049006 PMID: 7979837

4. Balabanova Y, Gilsdorf A, Buda S, Burger R, Eckmanns T, Gärtner B, et al. Communicable diseases prioritized for surveillance and epidemiological research: results of a standardized prioritization procedure in Germany, 2011. PLoS ONE. 2011;6(10):e25691. DOI: 10.1371/journal.pone.0025691 PMID: 21991334

5. Faensen D, Claus H, Benzler J, Ammon A, Pfoch T, Breuer T, et al. SurvNet@RKI--a multistate electronic reporting system for communicable diseases. Euro Surveill. 2006;11(4):100-3.PMID: 16645245

6. Freudenmann M, Kurz S, von Baum H, Reick D, Schreff AM, Essig A, et al. [Interdisciplinary management of a large Legionella outbreak in Germany]. Bundesgesundheitsblat Gesundheitsforschung Gesundheitsschutz. 2011;54(11):1161-9. DOI: 10.1007/s00103-011-1362-6 PMID: 22015788

7. von Baum H, Härter G, Essig A, Lück C, Gonser T, Embacher A, et al. Preliminary report: outbreak of Legionnaires disease in the cities of Ulm and Neu-UIm in Germany, December 2009January 2010. Euro Surveill. 2010;15(4):19472.PMID: 20122385

8. und die Mitarbeiter der Abteilung für Infektionsepidemiologie ,Poggensee G, Benzler J, Eckmanns T, Krause G. [On the 2007 edition of case definitions for the surveillance of notifiable infectious diseases in Germany]. Bundesgesundheitsblatt Gesundheitsforschung Gesundheitsschutz. 2006;49(12):118994. DOI: 10.1007/s00103-006-0088-3 PMID: 17149664

9. Institut RK. (RKI). Falldefinitionen des Robert Koch-Instituts zur Übermittlung von Erkrankungs- oder Todesfällen und Nachweisen von Krankheitserregern § 4 (2) des Gesetzes zur Verhütung und Bekämpfung von Infektionskrankheiten beim Menschen (Infektionsschutzgesetz - IfSG). [Case definitions of the Robert Koch Institute for the reporting of cases or deaths of communicable diseases and laboratory confirmation of infectious disease pathogens; $\$ 4$ (2) of the German Infection Protection Act]. Bundesgesundheitsblatt Gesundheitsforschung Gesundheitsschutz 2000 Nov 1;43(11):845-69. German. Available from: http://link.springer. com/article/10.1007\%2Fso01030050371

10. European Commission. Commission Implementing Decision 2012/506/EU of 8 August 2012 amending Decision 2002/253/ EC laying down case definitions for reporting communicable diseases to the Community network under Decision No 2119/98/EC of the European Parliament and of the Council. Official Journal of the European Union. Luxembourg: Publications Office of the European Union. 27.09.2012:L 262/1. Available from: http://eur-lex.europa.eu/LexUriServ/ LexUriServ.do?uri=0J:L:2012:262:0001:0057:EN:PDF

11. Entfernungen berechnen mit Javascript und Bing Maps [Distance calculator with Javascript and Bing Maps]. German. [Accessed September 2013]. Available from: http://www.mg2. de/map.html

12. International Organization for Standardization (ISO). ISO 11731. Water quality - Detection and enumeration of Legionella. Geneva: ISO; 1998. Available from: https://www.iso.org/obp/ ui/\#iso:std:iso:11731:ed-1:v1:en

13. Lück C. Legionella pneumophila : Genetische Diversität von Patienten- und Umweltisolaten.Bundesgesundheitsblatt Gesundheitsforschung Gesundheitsschutz. 2011;54(6):693-8. DOI: 10.1007/S00103-011-1282-5 PMID: 21626373

14. European Study Group for Legionella Infections (ESGLI). The EWGLI SBT database for the typing of Legionella pneumophila. London: Public Health England. [Accessed 1 Jan 2014]. Available from: http://bioinformatics.phe.org.uk/legionella/ legionella_sbt/php/sbt_homepage.php

15. IT.NRW Landesdatenbank, Information und Technik NordrheinWestfalen, Düsseldorf 2013, effective 18.11.2013. 2013.

16. European Centre for Disease Prevention and Control (ECDC). Legionnaires' disease in Europe, 2011. Stockholm: ECDC; 2013. Available from: http://ecdc.europa.eu/en/publications/ publications/legionnaires-disease-in-europe-2011.pdf

17. Planimeter ACME. Measure areas using Google Maps. [Accessed Sep 2013]. Available from: http://www.acme.com/ planimeter/

18. Siegmund-Schultze N. Legionelleninfektionen in Warstein: Größter Ausbruch in Deutschland. [Legionnaires' disease in 
Warstein: biggest outbreak in Germany]. Dtsch Arztebl Int. 2013;110(38):A-1736. German. Available from: https://www. aerzteblatt.de/archiv/literatur/146512

19. Siegmund-Schultze N. Seltener Legionellenstamm Auslöser für Epidemie in Warstein. [Rare subtype of Legionella as the cause of the epidemic in Warstein] Dtsch Arztebl Int. 2013;110(39):A1768. German. Available from: http://www.aerzteblatt.de/ archiv/146768/Seltener-Legionellenstamm-Ausloeser-fuerEpidemie-in-Warstein

20. Robert Koch Institute (RKI). Infektionsgeschehen von besonderer Bedeutung: Ausbruch von Legionärskrankheit in Warstein, Landkreis Soest. [Infectious disease incident of particular importance: Outbreak of Legionnaires' disease in Warstein, administrative district of Soest]. Epid Bull. 2013(35):345-364. German. Available from: https://www.rki. de/DE/Content/Infekt/EpidBull/Archiv/2013/Ausgaben/35_13. pdf?__blob=publicationFile

21. Federal Ministry of Justice. Gesetz zur Verhütung und Bekämpfung von Infektionskrankheiten beim Menschen (Infektionsschutzgesetz - IfSG). [Regulation on preventing and control of infectious diseases in humans (Act on protection against infection)]. Berlin: Bundesministeriums der Justiz und für Verbraucherschutz; 20 Jul 2000.Available from: http:// www.gesetze-im-internet.de/bundesrecht/ifsg/gesamt.pdf

22. Den Boer JW, Yzerman EP, Schellekens J, Lettinga KD, Boshuizen HC, Van Steenbergen JE, et al. A large outbreak of Legionnaires' disease at a flower show, the Netherlands, 1999. Emerg Infect Dis. 2002;8(1):37-43. DOI: 10.3201/ eido801.010176 PMID: 11749746

23. García-Fulgueiras A, Navarro C, Fenoll D, García J, GonzálezDiego P, Jiménez-Buñuales T, et al. Legionnaires' disease outbreak in Murcia, Spain. Emerg Infect Dis. 2003;9(8):915-21. DOI: 10.3201/eido908.030337 PMID: 12967487

24. Telford D, Partridge S, Cumming I, Smith A, Calvert N. The legionnaires' outbreak in Barrow-in-Furness, summer 2002.J Epidemiol Community Health. 2006;60(6):464-6. DOI: 10.1136/ jech.2005.037127 PMID: 16698973

25. Gosselin F, Duval JF, Simonet J, Ginevra C, Gaboriaud F, Jarraud $\mathrm{S}$, et al. Impact of the virulence-associated $M A b_{3} / 1$ epitope on the physicochemical surface properties of Legionella pneumophila sg1: An issue to explain infection potential? Colloids Surf B Biointerfaces. 2011;82(2):283-90. DOI: 10.1016/j.colsurfb.2010.08.040 PMID: 20889314

26. Nygård K, Werner-Johansen $\emptyset$, Rønsen S, Caugant DA, Simonsen $\varnothing$, Kanestrøm A, et al. An outbreak of legionnaires disease caused by long-distance spread from an industrial air scrubber in Sarpsborg, Norway. Clin Infect Dis. 2008;46(1):61 9. DOI: $10.1086 / 524016$ PMID: 18171215

27. Kusnetsov J, Neuvonen LK, Korpio T, Uldum SA, Mentula S, Putus T, et al. Two Legionnaires' disease cases associated with industrial waste water treatment plants: a case report. BMC Infect Dis. 2010;10(1):343. DOI: 10.1186/1471-2334-10-343 PMID: 21126333

28. Wedege E, Bergdal T, Bolstad K, Caugant DA, Efskind J, Heier $\mathrm{HE}$, et al. Seroepidemiological study after a long-distance industrial outbreak of legionnaires' disease. Clin Vaccine Immunol. 2009;16(4):528-34. DOI: 10.1128/CVI.00458-08 PMID: 19225076

29. Blázquez RM, Espinosa FJ, Martínez-Toldos CM, Alemany L, García-Orenes MC, Segovia M. Sensitivity of urinary antigen test in relation to clinical severity in a large outbreak of Legionella pneumonia in Spain.Eur J Clin Microbiol Infect Dis. 2005;24(7):488-91. DOI: 10.1007/S10096-005-1361-3 PMID: 15997369

30. Bundesrat. Beschluss des Bundesrates: Entschließung des Bundesrates zur Notwendigkeit immissionsschutzrechtlicher Regelungen der Anforderungen an Errichtung und Betrieb von Verdunstungskühlanlagen, Drucksache 795/13 (Beschluss) [Decision of the Federal Council: Resolution of the Federal Council on the need for pollution control law regulations of the requirements for the construction and operation of cooling systems]. Cologne: Bundesanzeiger; 14 Feb 2014. German. Available from: http://www.umwelt-online.de/ PDFBR/2013/0795_2D13B.pdf 